\title{
El aislamiento térmico de las viviendas reduce los síntomas respiratorios y sus consecuencias
}

Household Thermic insulation reduces respiratory symptoms and its consequences

Howden-Chapman T, et al. BMJ,2007 Feb 2007;334;460-464

\section{Objetivo}

Determinar si la aislación térmica en la vivienda incrementa la temperatura interior y mejora la salud de sus ocupantes.

\section{Diseño}

Intervención aleatorizada en "clusters" o racimos simple ciego y basada en la comunidad con análisis por intención de tratar.

\section{Lugar}

Siete comunidades de bajos ingresos en Nueva Zelanda, tres urbanas y cuatro rurales. Las temperaturas invernales en el día oscilan entre 10 y $16^{\circ} \mathrm{C}$, dos tercios de la casas son antiguas, de madera o de madera y concreto y solo un tercio están aisladas térmicamente.

\section{Participantes}

1350 viviendas que albergaban 4407 participantes (200 familias de cada comunidad que habitaban viviendas no aisladas y que al menos uno de sus miembros hubiera reportado síntomas respiratorios el año previo, o tuviera historia de asma, neumonías $u$ otras infecciones torácicas; y que no tuvieran planeado cambiar su habitat en los siguientes dos inviernos.

\section{Intervención}

Instalación de aislamiento térmico en techo y pisos, burletes en las ventanas y barreras de polietileno bajo los pisos para aislar la humedad en el grupo intervención. Las del grupo control fueron aisladas al final del estudio, después de la recolección de los datos.

\section{Medición de resultados principales}

Mejora de los indicadores de salud y el bienestar de los grupos familiares. Los participantes registraron su experiencia acerca de las características de las viviendas: temperatura, sensación térmica, humedad, uso de energía, aparición de hongos, conducta tabáquica, consultas a servicios de salud y tiempo perdido en sus actividades por enfermedades. Los autores junto a los médicos generales evaluaron el número, la duración y los códigos de las afecciones asistidas a través de un número único nacional de identificación del paciente. Las compañías de electricidad y gas reportaron el consumo de cada grupo familiar. Se ajustó por edad, sexo, región y características basales y se incluyó un análisis de costo beneficio.

\section{Resultados Principales}

El mejoramiento del ambiente interior de las viviendas se asocia con una mejora en el estado de salud. Ver tabla 1.

Tabla 1: resultados asociados a la mejoría en el aislamiento de las viviendas.

\begin{tabular}{l|c}
\multicolumn{1}{c|}{ Resultados } & Odds Ratio Ajustado (IC95\%) \\
\hline Grupo control & 1 \\
\hline Síntomas reportados & $0,50(0,38-0,68)$ \\
\hline Número de consultas & $0,73(0,62-0,87)$ \\
\hline Días perdidos de trabajo & $0,62(0,46-0,83)$ \\
\hline Días perdidos escolaridad & $0,49(0,31-0,80)$ \\
\hline
\end{tabular}

\section{Conclusiones}

El aislamiento térmico de las viviendas aumentó la temperatura al interior de las mismas y disminuyó la humedad en un $30 \%$. Las familias ahorraron en calefacción la mitad del costo de la intervención (£700). Los datos sobre consumo de energía sugieren que la mejoría en salud fue debida a una menor exposición prolongada a muy bajas temperaturas y alta humedad. Una intervención de un costo modesto se asocia a una mejoría significativa en la salud general, síntomas respiratorios y sensación de bienestar, y a una disminución de días de escolaridad y trabajo perdidos. Los efectos sobre hogares de pobre condición son acumulativos a lo largo de toda la vida, por lo que intervenciones sobre las condiciones de las viviendas tendrían un efecto multiplicador sobre la salud.

Palabras clave: viviendas, aislamiento, temperatura, salud, bienestar. Key words: houses, isolation, temperature, health, well-being.

\section{Comentario}

Hay pocos estudios sólidos en esta área sustantiva para la formulación de políticas públicas. Sin embargo, este trabajo demuestra que es posible evaluar intervenciones comunitarias con el rigor de un estudio controlado y aleatorizado. Es interesante destacar que al poner el foco de las mismas en poblaciones de bajos ingresos pueden potencialmente reducirse las inequidades en salud, debiéndose tener en cuenta la costoefectividad de las intervenciones a la hora de la toma de decisiones. Los problemas implicados en la gran "carga de enfermedad " de nuestras poblaciones son multicausales, lo que implica la necesidad de políticas sociales integradas (vivienda, salud, educación, intervenciones sociales directas, etc.) para lograr mejores y mayores resultados en salud. No es frecuente evaluar intervenciones comunitarias, en parte porque existe la tendencia a fragmentar las políticas sociales; y el diseño de políticas públicas fragmentadas, tan comunes en nuestras tierras, impide una evaluación más certera de su impacto en salud y bienestar.

Se hace necesario entonces, a la hora de las decisiones políticas, tener en cuenta la importancia de medir mediante trabajos metodológicamente consistentes, las medidas de mejoramiento de calida de vida con impacto en la salud.

Ricardo Sarandra. Médico de Familia [ Policlínico Modelo de Cipolletti. ricardo.sarandria@gmail.com ]

Sarandría R. El aislamiento térmico de las viviendas reduce los síntomas respiratorios y sus consecuencias. Evid. actual. práct. ambul; 10(3):70, May.Jun.2007. Comentado de: Howden-Chapman P, et. al. Effect of insulating existing houses on health inequality: cluster randomised study in the community. BMJ. 2007 Mar 3;334 (7591):434-5. PMID: 17324975

1. Rubinstein A. Editorial: El mejoramiento de la calidad y cantidad de vida: una tendencia secular Evidencia Actualización en la Práctica Ambulatoria - Vol. 10 Número 1: EneroFebrero 2007 